\title{
A Study on the Relationship between College Students' Personality and Their Eating Habits
}

\author{
Tzu-Hsing Wen, Wei-Ling Tchong, and Gregory S. Ching
}

\begin{abstract}
As we all know that the current generation is quite sensitive to issues regarding their physical appearance. Concepts such as ones' body weight have been of serious concern. On the other hand, school administrators are worried that students might neglect their health; hence, an inquiry into the common eating habits is accomplished. Employing the case study paradigm; this quantitative study is focus on understanding the factors influencing the students' eating habits. A total of 207 students of a technical vocational university in Taiwan participated in the study. Survey includes common eating habits; more specifically on the types and frequency of the food the students' eat. The Big Five Personality Scale is also administered to further understand the factors affecting the students' eating habits. Results show that the students' eating habits are affected by their various background demographics, such as gender, year level, study session, and personality. More importantly, results also show that the Applied Foreign Language students scored highest on the personality trait openness. Further additional implications on the Big Five Personality are also given. In sum, the current study provides the opportunity of opening up discussions explaining; perhaps not in whole, but in part why students act the way they are today.
\end{abstract}

Index Terms-Eating habits, college students, personality, case study.

\section{INTRODUCTION}

In recent years, the public in general have been valuing outward appearance more and more each day. As we read from the new, the number of people undergoing plastic surgery is at the all-time high. Beauty products have been getting better sales, even during these hard economic times [1]. It seems that people cares so much on their outward appearance than their budget.

In an educational setting, many have wondered why students today are quite different than those of the past decades. Students right now are very sensitive to issues with regards to their physical characteristics. Issues such as ones' body weight have been of serious concern. School administrators are worried that students might neglect their health; hence, an inquiry into the common eating habits is quite needed.

In light of these issues, this case study summarizes the

Manuscript received January 15, 2014; revised March 26, 2014. This work was supported in part by the Taiwan National Science Council under Grant number 102-2410-H-262-012-SS2.

T.-H. Wen is with the Center of Faculty Development, Taipei Medical University, Taipei City 110, Taiwan (e-mail: kksunnccu@gmail.com).

W.-L. Tchong and G. S. Ching are with the Graduate School of Educational Leadership and Development, Fu Jen Catholic University, New Taipei City 24205, Taiwan (e-mail: 061573@mail.fju.edu.tw, gregory_ching@yahoo.com). findings of a project focusing on understanding the factors influencing the students' eating habits. In addition, this study also uses the Big Five Inventory to determine the participants' personality and compares them to their eating habits.

\section{A. Research Questions}

With a primary objective of understanding the participants' eating orientations, initial research questions are generated as follows:

- What are the common eating habits of the students?

- What factors influence the students' eating habits?

- What is the relationship between the students' personality and their eating habits?

\section{LITERATURE REVIEW}

\section{A. Eating Habits}

Simply define "eating habits" is the way a person eats; this might be considered in terms of what types of food are eaten, in what quantities, and when. It is said that eating habits affect our health. According to Live Strong Foundation [2] healthy eating is consist of consuming the amount of foods that offer an ideal balanced diet between nutrition and energy that supports growth for children and metabolism for adults. Sample of healthy foods are those that promotes vitamins and minerals with less fats, cholesterol, sugar, and sodium.

In the other end of the spectrum, unhealthy foods or sometime referred to as junk foods are defined as any food that is not conducive to maintaining health [3]. Some sample of unhealthy foods is fat rich nourishment, foods low in fiber and vitamins, foods that are rich in salt and tropical oils, and many others. In essence, achieving healthy eating habits is as simply controlling one's food intake. More importantly, eating habits are form early in life; therefore, care must be taken in order to have a healthy lifestyle.

According to Juliet A. Boghossian [4]; a behavioral food expert and founder of foodology, "you are how you eat". Here she mentioned that people who eat fast tends to be ambitious; someone who use their brain more than their hearts. While, a person who eats slowly tends to do things that they want without caring for others [4]. Eating habits also differs in male and female [5]. In a survey of 488 college students, besides showing the lack of nutrients in their diets, results also show that male and female students tend to have varied nutritional needs, hence, differs in their eating habits [6]. Ultimately, eating habits tends to reflect one's attitude and behavior.

Food choices also affect one's eating habits; while many have said that eating habits is much related to outward 
appearance [7]. In a study Steptoe and his colleagues [8], their study compose of 358 adults of 18 to 87 years old; revealed that food choices are affected by nine factors, such as: health, mood, convenience, sensory appeal, natural content, price, weight control, familiarity, and ethical concern. Furthermore, statistical analysis shows that food choices are associated by the participants' gender, age, and income. In essence, a person's eating habits are affected by various internal and external factors. While, eating habits is able to reflect one's action, people should not forget that health is still wealth.

\section{B. Previous Related Studies with Regards to Personality and Eating Habits}

Various studies have mentioned that there are indeed significant relationships among a person's personality and their eating habits. In a study regarding personality and daily eating habits, results show that is a significant relationship among personality traits, moods, and eating pattern. Among the 562 women surveyed, results show that participants who experience anxiety and depression are more likely to become binge eaters [9].

In another study examining popular eating habits, within the 850 people surveyed; results show that eating habits are much concern with ones' age, gender, health, and longevity. While, personality traits have shown to possess relationships among food choices; such as openness and conscientiousness towards health related issues [10].

Other studies have shown that a person's personality is much related to their body mass index (BMI) [11]. This study collected the BMI data for a period of 14 years, results show that BMI levels during midlife are positively related to Neuroticism. On the other hand, BMI is negatively related to Openness, Agreeableness, and Conscientiousness. Furthermore, gender differences are also found on BMI of male respondents, wherein their weight is related to Extraversion. More importantly, Conscientiousness is found to be quite important for later weight gains as a person age [11].

In sum, numerous studies have depicted the relationship of personality and eating habits. Many studies have stated various significant correlations among the traits and outward appearance, more specifically a person's weight. With the varied perspective on eating habits, the current study shall try to pin-point in contrast further findings on eating habits with college students in Taiwan.

\section{RESEARCH Methodology}

\section{A. Research Design}

This research is designed as a case study, wherein the primary objective is to investigate a contemporary phenomenon within its real-life context [12]. Furthermore, this study is also designed as a descriptive research paradigm; a qualitative research that is concerned with how something that exists is related to some preceding event that has influenced or affected a present condition or event.

\section{B. Participants and Research Process}

As for the participants of the study; a total of 207 students of a technical vocational university in Taiwan are survey. The participants consists of 167 female $(80.70 \%)$ students with a mean age of 23 years old, while 40 male $(19.30 \%)$ students with a mean age of 28 years old. The high mean age is attributed to the participants coming from the weekend (on the job) course program. In addition, the participants are at the 1 st year $(75$ or $36.20 \%)$, 2nd year (35 or $16.90 \%)$, 4th year $(53$ or $25.60 \%$ ), and the newly graduate students ( 44 or $21.30 \%)$. Regarding their enrolled program, most of the students are in the morning session (134 or $64.70 \%$ ), while the remaining are from the evening (23 or $11.10 \%$ ) and weekend (50 or $24.20 \%$ ) sessions. With regards to their employment, a total of 118 or $57 \%$ of the participants stated that they are already working, while the remaining 89 or 43 are full-time students.

The current study is accomplished during the 2011 to 2012 school year. After the literature review and formation of the survey questionnaire, the survey was administered to 250 students with an effective return of 207 participants. For the survey validity, the overall Cronbach Alpha reliability of the survey is computed to be at .813; this is considered quite reliable.

\section{RESUlTS AND DisCUSSIONS}

\section{A. The Common Eating Habits of the Students}

The data collected from the 207 participants is analyzed using the statistical software SPSS. With regards to the participants' eating habits, results show that on average, students eat out 3 times a week. This is confirmed by the responds from 87 or $42 \%$ of the students stating that they tend to eat out a few times a week. One interesting finding is the notion of eating out when someone invites them with 78 or $37.70 \%$. This suggests that students are easily influenced by their peers; a trait quite related to Agreeableness.

In order to further analyze the background demography of the participants, the Big Five Personality Inventory is used to gather the participants' characteristics and traits. Results suggest that most students are quite inclined to the trait Openness. This means that students are willing to try on new experiences.

Further analyzing the data shows that female participants scored higher in Agreeableness and Neuroticism; suggesting that they are both sociable and emotional than their male counterparts. For the male participants, they scored higher in the traits Extroversion, Conscientiousness, and Openness. With respect to the students' program of study, weekend class students tend to be more emotional than the rest of the participants. While, the evening session students shows much potential in their Extroversion, Agreeableness, Conscientiousness, and Openness.

With respect to year level, $2^{\text {nd }}$ year (sophomore) students scored highest in Neuroticism, while the new graduates scored highest on the rest of the different personality traits. These results suggest that personality is somewhat related to a persons' age. Further analysis in the following sections shall provide an even deeper explanation among the correlations of the eating habits and personality.

Further data on the participants' eating habits are as 
follows. For the frequency of having breakfast, results show that participants eat breakfast for an average of five times per week. This result suggests students eat breakfast during week days. However, further follow-up shows that most of them eat breakfast when they have enough time to spare with 85 or $41.10 \%$.

With regards to having snacks, participants on average eat snacks three times a week. While, eat vegetable once a week. This is quite disappointing, wherein it is consider that vegetables are quite good for the students' health. Surprisingly, participants ranked highest among the eating habits are the inclusion of fruits in their meals with an average of almost four times a week. Data also shows that participants tend to eat fish for an average of twice a week. Drink soup almost four times a week, have a drink after meal for almost four times a week, eat desserts for twice a week, and have a salad for less than once a week (see Table I).

TABLE I: PARTICIPANTS' GENERAL EATING Habits ( $N=207)$

\begin{tabular}{|c|c|c|c|c|}
\hline Items & $n$ & $\%$ & Mean & $S D$ \\
\hline Brealfast (times per week) & & & 5.48 & 1.69 \\
\hline Don't eat breakfast & 46 & 22.20 & & \\
\hline Eat during work days & 24 & 11.60 & & \\
\hline Eat when I have enough time & 85 & 41.10 & & \\
\hline Eat breakfast everyday & 52 & 25.10 & & \\
\hline Snacks (times per week) & & & 2.80 & 2.08 \\
\hline Yes & 119 & 57.50 & & \\
\hline No & 88 & 42.50 & & \\
\hline Vegetables (times per week) & & & 1.19 & 1.70 \\
\hline Yes & 112 & 54.10 & & \\
\hline No & 95 & 45.90 & & \\
\hline Salad (times per week) & & & 0.73 & 1.07 \\
\hline Yes & 63 & 30.40 & & \\
\hline No & 114 & 69.60 & & \\
\hline Soup (times per week) & & & 3.71 & 2.20 \\
\hline Yes & 168 & 81.20 & & \\
\hline No & 39 & 18.80 & & \\
\hline Fish (times per week) & & & 2.08 & 1.56 \\
\hline Yes & 121 & 58.50 & & \\
\hline No & 86 & 41.50 & & \\
\hline Fruits (times per week) & & & 3.89 & 2.09 \\
\hline Yes & 171 & 82.60 & & \\
\hline No & 36 & 17.40 & & \\
\hline Desserts (times per week) & & & 2.42 & 2.02 \\
\hline Yes & 124 & 59.90 & & \\
\hline No & 83 & 40.10 & & \\
\hline Drinks (times per week) & & & 3.57 & 2.37 \\
\hline Yes & 152 & 73.40 & & \\
\hline No & 55 & 26.60 & & \\
\hline
\end{tabular}

\section{B. Factors That Influence the Students' Eating Habits}

To understand more deeply the factors that influence the students' eating habits statistical analysis are accomplished. With respect to the participants' gender differences and employment in eating habits. T-test results show that there exists a significant difference in eating habits of eating out for students' who are either working $(M=3.11, S D=1.12)$ and not-working $(M=2.75, S D=1.06)$ with $t(205)=2.32, p<.020$. This suggests that participants who are working have more time to eat out, than those who are not employed.

For the gender differences in eating habits, T-test results show that there exist significant differences among the female and male respondents on the eating habits such as eating fruits, drinking soups, and having desserts. While, the significant differences in the Big Five personalities, results shows that participants who are working are more inclined for the personality Extroversion, Agreeableness, Conscientiousness, and Openness. These are a good sign, which denotes that participants who are working are less emotional (since Neuroticism shows no significant difference in employment).
In addition, results also show that there is a significant gender difference with the personality factor Conscientiousness. Male $(M=24.70, S D=5.12)$ students are more conscientious than female $(M=22.64, S D=5.65)$ with $t(205)=2.11, p<.040$.

With respect to the relationship between student types and personality traits, analysis of variance (ANOVA) results show that there exist significant differences among the various study sessions for the traits Extraversion with $\mathrm{F}(3,204)=10.42, p<.000$, Agreeableness with $F(3,204)=7.71$, $p<.001$, Conscientiousness with $F(3,204)=22.86, p<.000$, and Openness with $F(3,204)=10.43, p<.000$. More detailed results are regular (morning) session students scored less on Extraversion, Agreeableness, Conscientiousness, and Openness than their evening and weekend counterparts.

With respect to the relationships between student types and eating habits, ANOVA results show that there exist significant differences among the various study sessions for the traits eating out with $F(3,204)=6.21, p<.002$, eating vegetables with $F(3,204)=3.23, p<.040$, and eating salad with $F(3,204)=4.03, p<.019$. More detailed results are regular (morning) session students scored less on eating out, eating vegetables, and eating salad than their evening counterparts.

With regards to the differences in students' year levels and their eating habits, ANOVA results show that there exist significant differences in the eating habits of eating out with $F(4,203)=30.44, p<.000$, vegetables with $F(4,203)=2.77$, $p<.043$, and having drinks with $F(4,203)=2.76, p<.043$ in freshmen students having less time to eat out as compared to the rest of the participants.

\section{The Relationship between the Students' Personality and Their Eating Habits}

Correlational results show that eating breakfast is negatively correlated with Neuroticism with .187 ( $p<.007)$. This suggests that when the value for eating breakfast increases, Neuroticism decreases. Additional results show that Agreeableness is positively correlated to having drinks with $.173(p<.013)$, which indicates that an agreeable person tends to drink more beverages. Furthermore, Conscientiousness is negatively correlated to the frequency of eating desserts with $.172(p<.013)$. This result suggests that participants who are quite conscious (responsible) would be more careful in eating sweets. This also signifies that when the frequency for eating dessert increases, Conscientiousness decreases.

\section{CONCLUSION}

The current study exemplifies the use of the Big Five Personality scale to understand EFL students' eating habits. This case study, though limited to the sample coming from a science and technology university, shows that students are more geared towards healthy lifestyles. As shown in the results that the frequency for eating breakfast is quite high (five times a week). Furthermore, students who are more Conscientious refrain from eating desserts (sweets). While eating out is much dependent on their employment status. In sum, individuals' eating habits would be much related to their 
background demographics. Hence, it is recommended that students should know the consequences of both good and bad eating habits; for ultimately, you are what and how you eat.

\section{REFERENCES}

[1] B. Kavoussi. (September 2013). The lipstick effect: Women spend more on beauty products during recessions, study says. [Online] Available:

http://www.huffingtonpost.com/2012/06/19/the-lipstick-effect-women -beauty-recessions_n_1606298.html.

[2] Live Strong. (September 2013). Definition of healthy eating. [Online]. Available

http://www.livestrong.com/article/396464-definition-of-healthy-eatin g/\#ixzz2CktaHZXU

[3] Collins Dictionary. (November 2013). Eating habits. [Online]. Available:

http://www.collinsdictionary.com/dictionary/english/eating-habits

[4] J. A. Boghossian. (November 2013). Food-ology: You are how you eat [Online]. Available: http://food-ology.com.p2.hostingprod.com/_advice_column

[5] S. R. Davy, B. A. Benes, and J. A. Driskell, "Sex differences in dieting trends, eating habits, and nutrition beliefs of a group of mid-western college students," Journal of American Dietetic Association, vol. 106, pp. 1673-1677, 2006.

[6] K. K. Li, R. Y. Concepcion, H. Lee, B. J. Cardinal, V. Ebbeck, E. Woekel, and R. T. Readdy, "An examination of sex differences in relation to the eating habits and nutrient intakes of university students," Journal of Nutrition Education and Behavior, vol. 44, pp. 246-250, 2012.

[7] D. Hayes and C. E. Ross, "Concern with appearance, health beliefs, and eating habits," Journal of Health and Social Behavior, vol. 28, pp. 120-130, 1987.

[8] A. Steptoe, T. M. Pollard, and J. Wardle, "Development of a measure of the motives underlying the selection of food: The food choice questionnaire," Appetite, vol. 25, pp. 267-284, 1995.
[9] W. M. Rebert, A. L. Stanton, and R. M. Schwarz, "Influence of personality attributes and daily moods on bulimic eating patterns," Addictive Behaviors, vol. 16, pp. 497-505, 1991.

[10] L. R. Goldberg and L. A. Strycker, "Personality traits and eating habits: The assessment of food preferences in a large community sample," Personality and Individual Differences, vol. 32, pp. 49-65, 2002.

[11] B. H. Brummett, M. A. Babyak, R. B. Williams, J. C. Barefoot, P. T. Costa, and I. C. Siegler, "NEO personality domains and gender predict levels and trends in body mass index over 14 years during midlife," Journal of Research in Personality, vol. 40, pp. 222-236, 2006

[12] R. K. Yin, Case study Research: Design and Methods, Newbury Park, CA: Sage, 1984.

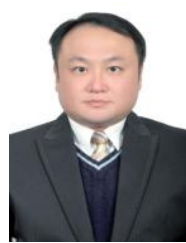

Wen-Tzu Hsing is an assistant research fellow in the Center of Faculty Development at the Taipei Medica University. He had been the director of the National Open University's Center of Teaching and Learning Development. His research interests include teaching methods, educational administration, school leadership, and school evaluation.

Wei-Ling Tchong is an assistant professor in the Graduate School of Educational Leadership and Development at Fu Jen Catholic University, Taipei, Taiwan. She is a graduate from the Phillips Graduate Institute in California, USA with a Doctor of Psychology in Organizational Consulting. Her research interests include holistic education development, school leadership and management, and educational leadership ethics.

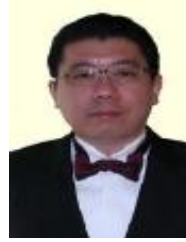

Gregory S. Ching is an assistant professor and is currently teaching at the Graduate School of Educational Leadership and Development in $\mathrm{Fu}$ Jen Catholic University, Taiwan. His research interest includes technology and education, globalization, higher education issues, international student mobility, and student engagement. 